\title{
GREEN ACCOUNTING: PEMANFAATAN BANK SAMPAH UNTUK MENINGKATKAN PEREKONOMIAN MASYARAKAT DI BANK SAMPAH UNILAK RIAU
}

\author{
Rina Maulina1, Ika Rahmadani ${ }^{2}$, Sari Maulida Vonna ${ }^{3}$, Linda Rahmazaniati ${ }^{4}$ \\ Program Studi Akuntansi - Universitas Teuku Umar \\ rinamaulina@utu.ac.id
}

\begin{abstract}
ABSTRAK
Salah satu permasalahan besar yang dialami kota-kota besar di Indonesia adalah persampahan. Sampah dapat diartikan sebagai konsekuensi adanya aktivitas kehidupan manusia.Tidak dapat dipungkiri, sampah akan selalu ada selama aktivitas kehidupan masih terus berjalan. Setiap tahunnya, dapat dipastikan volume sampah akan selalu bertambah seiring dengan pola konsumerisme masyarakat yang semakin meningkat. Kementerian Lingkungan Hidup mencatat rata-rata penduduk Indonesia menghasilkan sekitar 2,5 liter sampah per hari atau 625 juta liter dari jumlah total penduduk. Abdimas ini bertujuan agar mengubah mindset Mitra tentang paradigma pengelolaan sampah yang bertumpu pada pendekatan akhir sudah saatnya ditinggalkan dan diganti dengan paradigma baru. Paradigma yang menganggap sampah sebagai sumber daya yang mempunyai nilai ekonomis dan dapat dimanfaatkan, misalnya, untuk energi, kompos, pupuk, dan bahan baku industri. Pengelolaan sampah dapat dilakukan dengan pendekatan yang komprehensif. Dimulai dari hulu, yaitu sejak suatu produk yang berpotensi menjadi sampah belum dihasilkan. Dilanjutkan sampai ke hilir, yaitu pada fase produk sudah digunakan, sehingga menjadi sampah, yang kemudian dikembalikan ke media lingkungan secara aman. Tujuannya agar dapat mengurangi sampah di TPS/TPA dan mendorong pemberdayaan ekonomi masyarakat, melalui pemanfaatan sampah dengan program 3R (Reduce, Reuse dan Recycle).
\end{abstract}

Kata Kunci: Green Accounting, Bank Sampah, Perekonomian 


\section{ABSTRACT}

One of the big problems faced by big cities in Indonesia is solid waste. Garbage can be interpreted as a consequence of the activities of human life. It is undeniable that garbage will always exist as long as life activities continue. Every year, it is certain that the volume of waste will always increase along with the increasing consumerism of society. The Ministry of Environment noted that the average Indonesian population produces around 2.5 liters of waste per day or 625 million liters of the total population. This Abdimas aims to change Mitra's mindset about the waste management paradigm that is based on the final approach, it is time to leave it and replace it with a new paradigm. The paradigm that considers waste as a resource that has economic value and can be used, for example, for energy, compost, fertilizer, and industrial raw materials. Waste management can be done with a comprehensive approach. Starting from upstream, that is, since a product that has the potential to become waste has not been produced. Continued downstream, where the product has been used, so that it becomes waste, which is then returned to the environmental media safely. The goal is to reduce waste in TPS/TPA and encourage community economic empowerment, through the use of waste with the $3 R$ (Reduce, Reuse and Recycle) program.

Keywords: Green Accounting, Waste Bank, Economy

\section{PENDAHULUAN}

Salah satu permasalahan besar yang dialami kota-kota besar di Indonesia adalah persampahan. Sampah dapat diartikan sebagai konsekuensi adanya aktivitas kehidupan manusia.Tidak dapat dipungkiri, sampah akan selalu ada selama aktivitas kehidupan masih terus berjalan. Setiap tahunnya, dapat dipastikan volume sampah akan selalu bertambah seiring dengan pola konsumerisme masyarakat yang semakin meningkat. Kementerian Lingkungan Hidup mencatat rata-rata penduduk Indonesia 


\section{Jurnal ABDIMAS INDEPENDEN}

Vol. 2, No. 2, November 2021

menghasilkan sekitar 2,5 liter sampah per hari atau 625 juta liter dari jumlah total penduduk. Kondisi ini akan terus bertambah sesuai dengan kondisi lingkungannya. Menurut Statistik Sampah Indonesia (2012), jumlah sampah yang muncul di seluruh Indonesia mencapai 38,5 juta ton per tahun dengan dominan sampah tersebut berada di Pulau Jawa (21,2 juta ton per tahun). Undang-Undang Nomor 18 Tahun 2008 tentang Pengelolaan Sampah serta Peraturan Pemerintah Nomor 81 Tahun 2012 mengamanatkan perlunya perubahan paradigma yang mendasar dalam pengelolaan sampah yaitu dari paradigma kumpul- angkut-buang, menjadi pengolahan yang bertumpu pada pengurangan sampah dan penanganan sampah. Kegiatan ini bersifat social engineering yang mengajarkan masyarakat untuk memilah sampah, sekaligus menumbuhkan kesadaran masyarakat dalam pengolahan sampah secara bijak. Harapannya akan dapat mengurangi jumlah sampah yang diangkut ke TPA. Pembangunan bank sampah ini merupakan momentum awal dalam membina kesadaran kolektif masyarakat untuk mulai memilah, mendaur-ulang, dan memanfaatkan sampah. Hal ini penting, karena sampah mempunyai nilai jual dan pengelolaan sampah yang berwawasan lingkungan dapat menjadi budaya baru Indonesia.

\section{METODOLOGI}

\section{METODE YANG DITAWARKAN}

\section{Ceramah dan Tanya Jawab}

Metode ceramah dan tanya jawab ini digunakan untuk menyampaikan materi tentang penentuan potensi ekonomi sampah dan harga jual hasil olahan produk yang kompetitif serta pengantar pentingnya media sosial sebagai media promosi yang efektif dan efisien.

\section{Praktik}

Metode praktik ini digunakan untuk melatih kemampuan para pengelola UMKM, yakni pengelola UMKM dilatih membangun web pribadi 
untuk mempromosikan usahanya agar dikenal di tingkat lokal, nasional, dan internasional.

\section{Keterkaitan Kegiatan}

Kegiatan pengabdian masyarakat yang dilakukan pada tanggal 10 April 2021 bertempat di Universitas Lancang Kuning-Riau ini bertujuan memberikan pemahaman kepada masyarakat bagaimana cara meningkatkan perekonomian masyarakat melalui pengetahuan dan keterampilan yang diajarkan oleh pengelola bank sampah. Kegiatan pengabdian masyarakat ini merupakan kolaborasi antar perguruan tinggi dan melibatkan beberapa unsur masyarakat, diantaranya adalah:

1. RT/RW

2. Lurah

3. Pengurus dan personil Bank Sampah

4. Dosen Akuntansi

5. Mahasiswa terutama sebagai pendamping.

\section{Rancangan Evaluasi}

Evaluasi kegiatan pengabdian ini dilakukan dengan cara mengukur keberhasilan kegiatan dengan menetapkan tolak ukur sbb :

1. Meningkatnya pengetahuan dan keterampilan pengelola bank sampah tentang potensi ekonomi sampah dan penghitungan harga pokok produk sehingga pengelola tidak mengalami kerugian dalam penjualan produknya, indikatornya dapat dilihat dari hasil pre test dan post test.

2. Keberhasilan dalam penguasaan dan praktek terhadap materi perhitungan harga pokok (dibuktikan dengan peserta mampu menyusun harga pokok penjualan sesuai formula yang ada). 


\section{Jurnal ABDIMAS INDEPENDEN}

Vol. 2, No. 2, November 2021

\section{ASPEK PEMBIAYAAN}

\section{Aspek Teknik Operasional}

Mekanisme yang diberlakukan di Bank Sampah Unilak, yaitu dengan memilah sampah, masyarakat langsung mendapatkan keuntungan ekonomi, yang dapat diakses melalui beberapa program tabungan, antara lain:

1. Tabungan Regular, diambil sewaktu-waktu, minimal dalam jangka waktu satu bulan;

2. Tabungan Lebaran, diambil pada waktu menjelang lebaran untuk kebutuhan saat merayakan hari raya;

3. Tabungan Sekolah, diambil pada waktu ajaran sekolah untuk kebutuhan tahun ajaran baru siswa;

4. Tabungan Sembako, diambil bukan dalam bentuk uang tetapi dalam bentuk sembako sesuai dengan nilai tabungan;

5. Tabungan Lingkungan, yaitu tabungan dibentukan dalam berupa sarana untuk lingkungan seperti tong sampah, tanaman, komposter, gerobak, dll; dan

6. Tabungan Sosial, yaitu nilai tabungan akan disalurkan kepada Panti Asuhan, Pondok Pesantren, dan Lembaga sosial lainnya sesuai dengan permintaan nasabah.

\section{HASIL DAN PEMBAHASAN}

\section{DESKRIPSI}

\section{Pengelolaan Sampah}

Kodoatie (2003) mendefinisikan sampah adalah limbah atau buangan yang bersifat padat atau setengah padat, yang merupakan hasil sampingan dari kegiatan perkotaan atau siklus kehidupan manusia, hewan maupun tumbuh-tumbuhan. Sampah dalam ilmu kesehatan lingkungan (refuse) sebenarnya hanya sebagian dari benda atau hal-hal yang dipandang tidak digunakan, tidak dipakai, tidak disenangi atau harus 
dibuang, sedemikian rupa, sehingga tidak menganggu kelangsungan hidup. Menurut SK SNI T-13-1990 F, yang dimaksud dengan sampah adalah limbah yang bersifat padat terdiri dari zat organik dan anorganik.

Pengelolaan sampah merupakan bagian dari pengelolaan kebersihan. Pengertian bersih sebenarnya bukan hanya berarti tidak adanya sampah, melainkan juga mengandung pengertian yang mengarah ke tinjauan estetika. Terdapat tiga hal yang menjadi perhatian utama dan yang harus dipertimbangkan secara matang dalam pengelolaan sampah yaitu: identifikasi kondisi sistem pengelolaan sampah yang telah ada; definisi baik dan benar dalam hal pengelolaan sampah; dan pola kebijaksanaan pembinaan dan pengembangan. Pengelolaan sampah adalah semua kegiatan yang dilakukan untuk menangani sampah sejak ditimbulkan sampai dengan pembuangan akhir. Secara garis besar, kegiatan pengelolaan sampah meliputi: pengendalian timbulan sampah, pengumpulan sampah, pengangkutan, pengolahan dan pembuangan akhir (Sejati, 2004).

Penanganan sampah tidaklah mudah, melainkan sangat kompleks, karena mencakup aspek teknis, ekonomi dan sosiopolitis. Pengelolaan sampah adalah usaha untuk mengatur atau mengelola sampah dari proses pewadahan, pengumpulan, pemindahan, pengangkutan, pengolahan, hingga pembuangan akhir (DPU Cipta Karya, 1993). Sistem pengelolaan sampah adalah proses pengelolaan sampah yang meliputi lima aspek. Kelima aspek tersebut berkaitan erat satu dengan yang lainnya membentuk satu kesatuan, sehingga upaya untuk meningkatkan 2 "Dasar Pengelolaan Sampah Kota", dari http://www. docstoc.com/docs/34499795/DasarPengelolaan-SampahKota, diakses tanggal 2 Februari 2014. Pengelolaan persampahan harus meliputi berbagai sistem. Adapun aspek-aspek tersebut, yaitu: aspek kelembagaan, pembiayaan, pengaturan, peran serta masyarakat, dan teknik operasional (lihat Tabel. 1). Menurut SK SNI T-131990-F, pada dasarnya sistem pengelolaan sampah perkotaan dilihat 


\section{Jurnal ABDIMAS INDEPENDEN}

Vol. 2, No. 2, November 2021

sebagai komponen-komponen subsistem yang saling mendukung, saling berinteraksi, dan saling berhubungan satu sama lain. Kelima aspek tersebut merupakan prasyarat awal agar manajemen persampahan dapat terlaksana dengan baik. Satu aspek dengan aspek lainnya terkait erat dan saling mendukung.

Tabel 1.1 Aspek-Aspek Manajemen Persampahan

\begin{tabular}{|c|c|c|c|}
\hline No. & Aspek & Peran Pokok & Keterangan \\
\hline 1 & $\begin{array}{l}\text { Aspek } \\
\text { Kelembagaan }\end{array}$ & $\begin{array}{l}\text { menggerakan, } \\
\text { mengaktifkan dan } \\
\text { mengarahkan sistem }\end{array}$ & $\begin{array}{l}\text { Terdiri dari: } \\
\text { - Bentuk dan pola kelembagaan } \\
\text { - Sistem manajemen (perencanaan, pelaksanaan dan pengendalian } \\
\quad \text { untuk jenjang strategis, teknik maupun operasional) }\end{array}$ \\
\hline 2 & $\begin{array}{l}\text { Aspek } \\
\text { Pembiayaan }\end{array}$ & $\begin{array}{l}\text { merupakan komponen } \\
\text { sumber dalam arti supaya } \\
\text { sistem mempunyai kinerja } \\
\text { yang baik }\end{array}$ & $\begin{array}{l}\text { struktur pembiayaan terdiri dari: } \\
\text { - } \text { anggaran } \\
\text { - } \text { alternatif sumber pendanaan }\end{array}$ \\
\hline 3 & $\begin{array}{l}\text { Aspek } \\
\text { Pengaturan } \\
\text { (dasar } \\
\text { hukum) }\end{array}$ & $\begin{array}{l}\text { komponen yang menjaga } \\
\text { pola/dinamika sistem agar } \\
\text { dapat mencapai sasaran } \\
\text { secara efektif. }\end{array}$ & $\begin{array}{l}\text { Fungsi dari peraturan: } \\
\text { - Sebagai landasan pendirian instansi pengelola (Dinas, } \\
\text { Perusahaan Daerah dan lainnya) } \\
\text { - Sebagai landasan pemberlakuan struktur tarif } \\
\text { - Sebagai landasan ketertiban umum (masyarakat) dalam } \\
\text { pengelolaan persampahan }\end{array}$ \\
\hline 4. & $\begin{array}{l}\text { Aspek } \\
\text { Peran Serta } \\
\text { Masyarakat }\end{array}$ & $\begin{array}{l}\text { komponen yang tidak } \\
\text { bersifat subsistem tapi } \\
\text { terikat erat sebagai } \\
\text { penyediaan kapasitas kerja } \\
\text { maupun pendanaan. }\end{array}$ & $\begin{array}{l}\text { Bentuk peran serta masyarakat dalam: } \\
\text { - Teknis operasional pengumpulan sampah dari mulai sumber } \\
\text { sampai pembuangan akhir } \\
\text { - Pendanaan }\end{array}$ \\
\hline 5. & $\begin{array}{l}\text { Aspek Teknik } \\
\text { Operasional }\end{array}$ & $\begin{array}{l}\text { komponen yang paling } \\
\text { dekat dengan obyek } \\
\text { pengelolaan sampah }\end{array}$ & $\begin{array}{l}\text { Terdiri dari sarana, prasarana, perencanaan, dan tata cara teknik } \\
\text { operasional pengelolaan sampah untuk kegiatan: } \\
\text { - Pewadahan } \\
\text { - Pengumpulan } \\
\text { - Pengangkutan } \\
\text { - Pembuangan akhir }\end{array}$ \\
\hline
\end{tabular}

\section{Pengelolaan Sampah Berbasis Masyarakat}

Kastaman (2004) dalam Koesrimardiyati (2011) mendefinisikan pengelolaan sampah berbasis masyarakat sebagai suatu pendekatan pengelolaan sampah yang didasarkan pada partisipasi aktif masyarakat. Pemerintah dan lembaga lainnya hanyalah sebagai motivator dan fasilitator. Douglas, dkk. (1994) menyatakan bahwa pengelolaan lingkungan hidup memerlukan adanya fasilitasi dan implementasi upaya berbasis masyarakat sebagai suatu strategi pemberdayaan dan peningkatan akses mereka kepada sumber daya lingkungan hidup yang penting, terutama tanah, infrastruktur, dan pelayanan. Pengelolaan sampah berbasis 
masyarakat sangat penting, karena kegiatan tersebut dilakukan oleh anggota komunitas itu sendiri. Mereka mengambil keputusan yang terkait dengan kehidupan mereka sendiri. Hal ini akan menjadi lebih tepat guna jika disesuaikan dengan kebutuhan lokal serta prioritas dan kapasitas mereka (Sutandyo-Buchholz, 2005 dalam Koesrimardiyati, 2011).

Pendekatan pengelolaan sampah $3 R$ yang diterapkan oleh Bank Sampah Unilak berpedoman pada Peraturan Menteri Lingkungan Hidup No 13 Tahun 2012, membuka pandangan dan wawasan baru bagi masyarakat dalam mengelola sampah. Sampah tidak lagi dipandang barang tidak berguna, akan tetapi melalui pendekatan 3R, sampah dapat dijadikan sesuatu yang bernilai tambah. Oleh karena itu, keterlibatan masyarakat untuk berperan serta dalam kegiatan daur ulang sangat diperlukan, baik sebagai produsen, maupun sebagai anggota masyarakat penghasil sampah. Sampah akan memiliki nilai ekonomis apabila berada dalam jumlah mencukupi untuk diperdagangkan atau diproses lebih lanjut sebagai barang-barang ekonomi, baik sebagai bahan baku (daur ulang) maupun sebagai komoditas perdagangan. Apabila masyarakat selaku penghasil sampah melakukan peran serta dalam pengelolaan sampah, misal 3R; maka menampung dan memasarkan sampah tersebut perlu suatu wadah. Disinilah dapat dilihat pentingnya Bank Sampah sebagai sarana bagi masyarakat untuk menabung, meningkatkan sosio-ekonomi, sekaligus memberdayakan masyarakat dalam pengelolaan sampah.

\section{Bank Sampah di Indonesia}

Strategi nasional kebijakan penanganan sampah melalui program 3R adalah: pengurangan sampah, penanganan sampah, pemanfaatan sampah, peningkatan kapasitas pengelolaan, dan pengembangan kerja sama. Sedangkan UU No. 18 Tahun 2008 tentang Pengelolaan Sampah mengatakan bahwa pengelolaan sampah rumah tangga, terdiri dari pengurangan sampah sampah dan penanganan sampah. Pengurangan 


\section{Jurnal ABDIMAS INDEPENDEN}

Vol. 2, No. 2, November 2021

sampah yang dimaksud, meliputi: pembatasan timbulan sampah, daur ulang sampah dan pemanfaatan kembali sampah.

Pengelolaan sampah di tingkat komunitas melalui Bank Sampah, pertama kali dilakukan sejak 2008 lalu di Desa Badegan Kabupaten Bantul, Provinsi Daerah Istimewa Yogyakarta, dengan nama Bank Sampah Gemah Ripah. Ide pendiriannya tercetus karena banyaknya kasus demam berdarah di Bantul, dan kasusnya meningkat tajam seiring dengan banyaknya tumpukan sampah. Setelahnya, daerah-daerah lain juga turut mendirikan Bank Sampah, dan dari waktu ke waktu perkembangannya makin meningkat. Kementerian Lingkungan Hidup mengembangkan konsep Bank Sampah di berbagai provinsi. Statistik perkembangan pembangunan Bank Sampah di Indonesia pada bulan Februari 2012 menunjukkan sebanyak 471 Bank Sampah telah berjalan. Dengan jumlah penabung sebanyak 47.125 orang dan jumlah sampah yang terkelola adalah $755.600 \mathrm{~kg} /$ bulan dengan nilai perputaran uang sebesar Rp1.648.320.000,00 perbulan. Pada Mei 2012, angka statistik ini meningkat menjadi 886 Bank Sampah, dengan jumlah penabung sebanyak 84.623 orang dan jumlah sampah yang terkelola sebesar $2.001 .788 \mathrm{~kg} /$ bulan serta menghasilkan uang sebesar Rp3.182.281.000,00 perbulan (Kementerian Lingkungan Hidup, 2013).

\section{PENJELASAN}

\section{BANK SAMPAH UNIVERSITAS LANCANG KUNING}

\section{Sejarah Pendirian}

Bank sampah Unilak baru diresmikan akhir Maret 2021 yang lalu. Akan tetapi aktifitas Bank Sampah Unilak sudah beroperasi jauh sebelum diresmikan. Telah banyak manfaat yang diambil oleh masyarakat dengan adanya bank sampah ini terutama pada kelompok-kelompok masyarakat binaan Universitas Lancang Kuning. 


\section{Aspek Kelembagaan}

BSU merupakan lembaga kegiatan kampus dengan izin rektor Universitas Lancang Kuning Nomor 047/Unilak/OT/ Tahun 2021 Bentuk kelembagaan BSU sudah sesuai dengan aturan yang berlaku, meskipun Peraturan Menteri Lingkungan Hidup Nomor 13 Tahun 2012 tentang Pedoman Pelaksanaan Reduce, Reuse, dan Recycle melalui Bank Sampah baru dikeluarkan oleh Pemerintah pada tanggal 7 Agustus 2012. Lembaga ini dibentuk atas kesadaran dosen akuntansi Unilak yang memiliki tanggung jawab terhadap masalah sampah.

BSU didirikan atas kerjasama antara Unilak dengan Pemerintah Kota Pekanbaru dan CSR PT. Cevron Indonesia. BSU diharapkan dapat menjadi wadah untuk membina, melatih, mendampingi, serta membeli dan memasarkan hasil kegiatan pengelolaan sampah dari hulu (sumber), dalam rangka pengurangan sampah di TPS/TPA; dan pemberdayaan ekonomi masyarakat, dengan memanfaatkan sampah dengan 3R (reduce, reuse, recycle); serta perubahan perilaku masyarakat menuju lingkungan Kota Pekanbaru yang bersih, sejuk, dan manfaat. Adapun struktur organisasi BSU adalah sebagai berikut: 


\section{Jurnal ABDIMAS INDEPENDEN}

Vol. 2, No. 2, November 2021

\begin{tabular}{|r|l|l|}
\hline No & \multicolumn{1}{|c|}{ Nama } & \multicolumn{1}{|c|}{ Jabatan } \\
\hline 1 & Dr. Junaidi, S.S., M.Hum. (Rektor Unilak) & Pelindung \\
\hline 2 & Ir. Latifa Siswati, M.P. (Ketua LPPM Unilak) & Pembina \\
\hline 3 & Dr. Jeni Wardi, S.E., M.Ak., Ak., CA & Ketua \\
\hline 4 & Dr. David Setiawan, M.T. & Sekretaris \\
\hline 5 & Ambar Tri Ratna, S.Hut., M.Si. & Bendahara \\
\hline 6 & Guntoro, S.T., M.Kom. & Koordinator Divisi Administrasi \\
\hline 7 & Dodi Sukma, S.Hut., M.Si & Anggota Divisi Administrasi \\
\hline 8 & Dr. Anto Ariyanto, S.Si., M.Si. & Koordinator Divisi Kompos \\
\hline 9 & Sri Utami, S.P., M.P. & Anggota Divisi Kompos \\
\hline 10 & Dr. Ervayenri, M.Si. & Anggota Divisi Kompos \\
\hline 11 & Ir. Latifa Siswati, M.P. & Koordinator Divisi An Organik \\
\hline 12 & Dr. Rina Novia Yanti, S.Hut., M.Si. & Anggota Divisi An Organik \\
\hline 13 & Alexsander Yandra, S.IP., M.Si. & Koordinator Divisi Pemasaran \\
\hline 14 & Dr. Indra Purnama, M.Sc. & Anggota Divisi Pemasaran \\
\hline 15 & Hamzah, S T, M T, Ph D & Divisi Operacional Lapangan \\
\hline 16 & Jufrinata, S.H. & Anggota Operasional Lapangan \\
\hline 17 & Suwito, S.Hum. & Anggota Operasional Lapangan \\
\hline
\end{tabular}

Pengambilan sampah perhari dari 15 lokasi kelompok, dengan menggunakan tiga armada mobil pick up, rata-rata kapasitas sampah mencapai hingga +1 ton. Jumlah ini akan terus bertambah, seiring dengan meningkatnya keaktifan kelompokkelompok yang saat ini masih tahap pembelajaran pemilahan.

Kegiatan BSU juga mampu menarik kalangan swasta untuk terlibat di dalamnya melalui kegiatan Corporate Social Responsibility (CSR). Partisipasi dalam berbagai macam bentuk mulai dari pemberian dana cash sampai dengan bantuan hadiah-hadiah dalam penyelenggaraan lomba kebersihan yang dilaksanakan oleh BSU. Adapun perusahaan swasta dan BUMD yang telah berpartisipasi di antaranya: PT. PLN, Indo Maret, Bank Indonesia, Bank Mandiri, Bank Danamon, dsb. Pihak Bank Sampah juga mengembangkan kerjasama dengan PLN Jawa Timur, dimana pembayaran rekening listrik dapat menggunakan sampah.

Sementara itu, terkait dengan teknik operasional, Bank Sampah Unilak mengalami kendala mengenai gudang/penyimpanan. Gudang yang 
biasa digunakan sebagai tempat menampung sampah sementara yang ada di unit-unit Bank Sampah Unilak masih belum memadai. Sebagian besar masih menggunakan garasi/teras rumah, kantor RW, pos kamling, atau bangunan kosong di wilayahnya. Padahal gudang untuk menampung sampah di unit Bank Sampah Unilak - Riau ini merupakan prasarana yang harus ada dan mempunyai peranan vital untuk menjaga kualitas sampah. Sehingga, sangat diharapkan kedepan permasalahan terkait gudang/penyimpanan ini memperoleh jalan keluarnya.

\section{KESIMPULAN}

Program pengelolaan sampah mandiri melalui Bank Sampah, telah menjadi salah satu alternative solusi bagi pemerintah dan masyarakat di Indonesia. Solusi untuk mengurangi peningkatan volume sampah yang semakin tidak terkendali. Sosialisasi pengelolaan sampah mandiri melalui Bank Sampah, sampai saat ini masih gencar dilakukan oleh pemerintah kota maupun kabupaten. Selain memberikan dampak positif bagi lingkungan, dalam proses pengelolaannya, bank sampah memiliki mekanisme relasi dan jaringan sosial yang bernilai ekonomis. BSU dapat berperan sebagai dropping point bagi produsen untuk produk dan kemasan produk yang masa pakainya telah usai. Sebagian tanggung jawab pemerintah dalam pengelolaan sampah, menjadi tanggungjawab pelaku usaha pula. Dengan menerapkan pola ini, volume sampah yang dibuang ke TPA diharapkan dapat berkurang. Aspek-aspek manajemen persampahan apabila diterapkan dengan optimal di BSU akan turut membantu pengelolaan sampah di Kota Pekanbaru. Penerapan prinsip 3R sedekat mungkin dengan sumber sampah juga diharapkan dapat menyelesaikan masalah sampah secara terintegrasi dan menyeluruh, sehingga tujuan akhir kebijakan Pengelolaan Sampah Indonesia dapat dilaksanakan dengan baik. 


\section{Jurnal ABDIMAS INDEPENDEN}

Vol. 2, No. 2, November 2021

\section{UCAPAN TERIMA KASIH}

Tim pengabdian masyarakat mengucapkan terima kasih kepada pihak-pihak yang telah memberikan dukungan terlaksananya kegiatan ini antara lain:

1. Syahrijal Hidayat, S.E.,M.Ak (Selaku Ketua Pelaksana Kegiatan Pengabdian Masyarakat)

2. Dr. Jeni Wardi, S.E.,Ak.,M.Ak.,CA (Selaku Mitra Pengelola Bank Sampah Universitas Lancang Kuning - Riau)

3. Dr. Arfan Ikhsan Lubis, S.E.,M.Si (Selaku Ketua Umum ADAI)

4. Dekan Fakultas Ekonomi Universitas Teuku Umar.

5. Ketua Prodi S1 Akuntansi Fakultas Ekonomi Universitas Teuku

\section{DAFTAR PUSTAKA}

Aryeti. 2011. Peningkatan Peranserta Masyarakat Melalui Gerakan Menabung pada Bank Sampah di Kelurahan Babakan Surabaya, Kiaracondong Bandung. Jurnal Permukiman, Vol. 6 No. 1 April 2011: 40-46.

Azwar, Azrul. 1990. Pengantar Ilmu Lingkungan. Jakarta: Mutiara Sumber Widya. Crememisinoff, Nicholas P. 2003. Handbook of Solid Waste Management and Waste Minimization Technology, Amsterdam: Butterwoth-Heinemann.

Douglas, M., Lee, Y.S., dan K. Lowry. 1994. Urban Poverty and Environmental Management in Asia.

Asian Journal of Environmental Management 2 (1). Hadiwiyoto, Soewedo. 1983. Penanganan dan Pemanfaatan Sampah. Jakarta: Yayasan Idayu.

Hartanto. Widi. 2006. Kinerja Pengelolaan Sampah Di Kota Gombong Kabupaten Kebumen. Thesis. Program Pascasarjana Magister Teknik Pembangunan Wilayah dan Kota Universitas Diponegoro Semarang. 
Inoguchi, Takashi, Edward Newman, Glen Paoletto. 2003, Kota dan Lingkungan Pendekatan Baru Masyarakat Berwawasan Ekologi, Jakarta: Pustaka LP3ES.

Kodoatie, Robert J. 2003. Manajemen dan Rekayasa Infrastruktur. Yogyakarta: Pustaka Pelajar. Nag, A. Vijayakumar. 2005. Environmental Education and Solid Waste Management, New Delhi: New Age International Publisher.

Riduwan. 2002. Skala Pengukuran Variabel-Variabel Penelitian. Bandung: Penerbit Alfabeta. Sejati, Kuncoro. 2009. Pengolahan Sampah Terpadu, Yogyakarta: Kanisius. Simamora, Bilson. 2004. Panduan Riset Perilaku Konsumen. Jakarta: Gramedia Pustaka.

Sinulingga, Budi D. 1999. Pembangunan Kota Tinjauan Regional dan Lokal. Jakarta:Pustaka Sinar Harapan.

Suriawiria. U. 1980. Sampah Krisis Baru di Tahun 2000-an. Jurnal Widyapura No. 4 Tahun III. KP2L. Jakarta. Tchobanoglous,

H.H, Theisen \& S.A. Vigil. 1993. Integrated Solid Waste Management. New York: McGraw-Hill International Edition. Widyatmoko, Sintorini. 2002. Menghindari, Mengolah dan Menyingkirkan Sampah. Jakarta: Abadi Tandur. 